\title{
An integrated tool to support engineers for WMSDs risk assessment during the assembly line balancing
}

\author{
Raffaele Di Benedetto ${ }^{\mathrm{a},}$ and Michele Fanti ${ }^{\mathrm{b}}$ \\ ${ }^{a}$ CEO Centro Italiano di Ergonomia, C.so Italia, 20, 56125, Pisa, Italy \\ ${ }^{\mathrm{b}}$ CTO Centro Italiano di Ergonomia, C.so Italia, 20, 56125, Pisa, Italy
}

\begin{abstract}
This paper wants to present an integrated approach to Line Balancing and Risk Assessment and a Software Tool named ErgoAnalysis that makes it easy to control the whole production process and produces a Risk Index for the actual work tasks in an Assembly Line. Assembly Line Balancing, or simply Line Balancing, is the problem of assigning operations to workstations along an assembly line, in such a way that the assignment be optimal in some sense. Assembly lines are characterized by production constraints and restrictions due to several aspects such as the nature of the product and the flow of orders. To be able to respond effectively to the needs of production, companies need to frequently change the workload and production models. Each manufacturing process might be quite different from another. To optimize very specific operations, assembly line balancing might utilize a number of methods and the Engineer must consider ergonomic constraints, in order to reduce the risk of WMDSs. Risk Assessment may result very expensive because the Engineer must evaluate it at every change. ErgoAnalysis can reduce cost and improve effectiveness in Risk Assessment during the Line Balancing.
\end{abstract}

Keywords: assembly lines, line balancing, ergonomics, OCRA index, risk assessment

\section{Introduction}

Industrial processes are characterized by constraints and restrictions associated with, among other things, product, production layout, the flow of orders. In this context, it is mandatory to be able to give timely responses to needs of production. The balance of the production lines let the engineer distribute the workload on individual workstations, based on actual requests. This activity takes into account primarily the needs of production and defers to other figures and subsequent activities the risk assessment for biomechanical overload of workers. As a consequence of this approach, the workload is often distributed without taking into account the risk of biomechanical overload of the muscular skeletal system.

Consider the ergonomic aspects of the production means an increase in the worker's performance and a greater possibility of achieving economic goals. The purpose of this paper is to present an integrated ap- proach to balancing of production lines, using a software tool, that allows the production process Engineer to consider the ergonomics of workstations since the balancing stage of production lines. This involves a greater control of the entire process flow and the integration between different business functions with a significant operational and productive advantage. This approach has been tested in different working contexts, including the automotive sector, the White and the metalworking industry. Methodologies used are international standards developed for specific Risk Assessment. The approach allows the use of work analysis tools in association with risk assessment tools in order to achieve the two goals: Line Balancing and Risk Assessment. A description of the results of the use of the Software tool and the methodology is presented.

\footnotetext{
* Corresponding author. E-mail: r.dibenedetto@centro-ergonomia.it.
} 


\section{Health, safety and economic goals}

One of the main aims of the interventions in the field of Ergonomics in the workplaces is to be able to combine the improvement of working conditions with economic efficiency and productivity. This goal is rarely achieved through an integrated process that covers both the production and ergonomic aspects since the design stage of the production process.

Ergonomic approaches that are introduced after the requests from employees or even worse after the first diagnoses of work-related health problems follow a corrective manner, and therefore cannot fulfill this concern. Especially the integration of corrective measures into completed work design is in most cases difficult and high priced. Costs arising from this incorrect approach are significant: absence due to illness of staff members is connected to premium rates, breaking-in costs of new staff members, capital expenditure, insurance contributions of possible unused capital equipment, or increased costs for planning and controlling on the side of management.

In industries that use assembly lines, an important part of the definition of the production process is the so called line balancing. It is the problem of assigning operations to workstations along an assembly line, in such a way that the assignment be optimal in some sense. Assembly line activities are very critical because there is a short time task activity with a production of a high number of units per shift. It means to repeat the same movements for hundreds of times in a day and it means high possibility to develop Work-Related Musculoskeletal Disorder (WMSD) if not monitored.

For this reason in this environment it is very important to consider the biomechanical ergonomic analysis and workplace evaluation since the design phase. The ergonomic intervention at this stage, allows a greater control of the parameters involved and a more effectiveness at a reduced cost.

Competitiveness (in particular for SME) is based on the capacity to increase the processes efficiency, keeping the processes quality high and guarantying ethics working condition (safety and wellbeing). Combining Productivity and Ergonomics is the challenge, but today these aspects are not considered adequately at the production processes design phase.

\subsection{Problem Definition}

In the field of productivity many optimization techniques are available on the market, generally based on MTM (Method and Time Measurement) methodologies. MTM analyzes work tasks in order to determine how long a well-trained industrial worker will require to complete a certain task at a rate that can be sustained for a shift. This means focusing the analysis on productivity parameters only.

On the side of the ergonomics optimization there are many methods (and standards) for analysis and evaluation of existing workplaces but the existing tools are very complex and expensive and product oriented (not very good for production processes). Moreover, the ergonomics analysis on workplaces and production processes is minimal because of a complex and fragmented approach and because not linked to economics parameters. Sometimes ergonomics is verified only for safety reasons or to complain to regional rules and laws requirement.

So, the needs are addressed to a fast and reliable methodology of analysis for the design phases of the production processes and workplaces, as well as to the availability of a software tool able to satisfy an holistic approach for ergonomics evaluation, considering the areas of biomechanics, organization, environments.

\subsection{State of the art}

WMDs Risk assessment methodologies have been developed independently by researchers to address the increasingly diseases connected with workplaces. The approach is almost always voted to the risk assessment in an actual workplace. The international standard organizations have delivered standards to address typical job situations. ISO 11228 international standards define standard guidelines and methodologies for risk assessment: NIOSH, Strain Index, Reba, Rula, OCRA, Snook and Ciriello, CTD risk index, ACGI HAL, OREGE, OSHA are only some of the methodologies mostly used around the world[5,8].

Current research, which is related to methods engineering and the design of manual workstations, branches into two domains. The first deals with more technical aspects of anthropometric modeling and simulation of human movement. The other domain deals with the development of methodologies set to exploit the technology in design application such as CAE (Computer Aided Engineering). Several attempts have been made to apply CAE to methods engineering and workstation design. Commonly, systems consist of a database of workstation elements (such as bins and tools) and anthropometric data 
combined with an MTM analysis module and a Safety and Health module.

Optimization of ergonomic and economic measures can be achieved through an interactive process of small adjustments to workstation parameters such as bin sizes, arrangement of bins and tools in the workplace, and product design. Therefore, these methods and SW Tools focus on finding a good solution relative to both measures rather than finding a strict optimal solution.

As for methodologies, the Automotive Assembly Worksheet (AAWS) [1, 7], drawn up in Germany, is a checklist for assessing static postures, action forces, manual material handling, and extra strains in assembly lines.

Tools and software tools are available on the market but they are specific for particular application. In particular, for the risk assessment in a workstation the reference tool in Italy is the commercial software OSTools [3].

In the field of time and methods analysis (MM techniques) there are a lot of software tools very simple but also very specialized for Time analysis and not including ergonomics analysis. Only one software MTMergonomics[5] developed in this field is able to carry out the ergonomic evaluation and MTM analysis despite the software is mainly dedicated to the MTM techniques.

Only in very few cases the analysis is supported by a video of the work task. Video task analysis of performed work activity, should be the base for the evaluation and the optimization of the work methods and ergonomics. The possibility to carry out a video task analysis and get from this analysis information necessary for ergonomic evaluation and process optimization is one of the technological gap to bridge in the ergonomic area evaluation.

\section{Methodological formulation}

The idea at the base of ErgoAnalysis is that a work task can be split into a number of operations that are characterized by their own risk factors or Intrinsic Risk Factors (IRF) and the duration of the exposure. When you compose the work task as the combination of the operations, you can achieve the result of a risk index for the workstation by a simple combination of the IRF using international standards methodologies (Multitask OCRA Index, Composite Lifting Index, etc.). This approach to the problem of risk assessment is very similar to the one used by all Predeter- mined Time Systems (PTS) for Line Balancing, such as MTM. In this case the methodology assigns times to determine how long a skilled worker should normally take to carry out a work operation. Then the Process Engineer assign operations to the workstations in order to define the best work tasks.

In both cases, Risk Assessment and Line Balancing, the work task is divided into operations with some characteristics that are IRF, for Risk Assessment, and Duration, for Line Balancing. When the Industrial Process Engineer combines operations, the result is either a Complex Risk Index (CRI), either the Duration of the work task.

Two more aspects have to be examined in order to understand how this methodology can be applied to the actual industrial reality: a) how to determine the IRF for each operation and $b$ ) how to determine the CRI for each workstation. The most complicated Risk Assessment is the one connected to Upper Limb WMSDs (UL-WMSDs) that is the most relevant in Assembly Lines. In Assembly Lines, repetitiveness of tasks is one of the most important risk factors: the same movements are made at every single task activity for the entire shift duration. The international standard ISO 11228-3[21] defines the methodology to use for Upper Limb risk assessment. It refers to the OCRA Index[2] that produces a risk index that is based on the ratio between the Actual Technical Actions (ATA) and the Reference Technical Actions (RTA). We will proceed our exposition only for ULWMSDs taking into account the International Standards ISO 11228-3 that define the OCRA Index as the preferred method for UL-WMSDs Risk Assessment. OCRA Index for $n$ tasks is defined as the ratio between overall ATA $\left(n_{A T A}\right)$ and overall RTA in the shift $\left(n_{R T A}\right)$ :

$$
\text { OCRA Index }=n_{A T A} / n_{R T A}
$$

In Assembly Lines the same work task is done a number of times during shift duration. The number of repetition $\mathrm{N}$ is the ratio between the shift duration and the duration of the work task. In this way, if we consider the single workstation, we can approach to the Risk Assessment as a Multitask OCRA Index of $\mathrm{N}$ tasks that are all the same! The examination of Risk Factors for the single Work Task let us obtain the CRI.

An analogue approach can be used for NIOSH Lifting Index (ISO 11228-1)[4, 19] and awkward posture Risk Assessment [12]12-18]. 


\section{ErgoAnalysis: a software tool to support the engineer in line balancing and risk assessment}

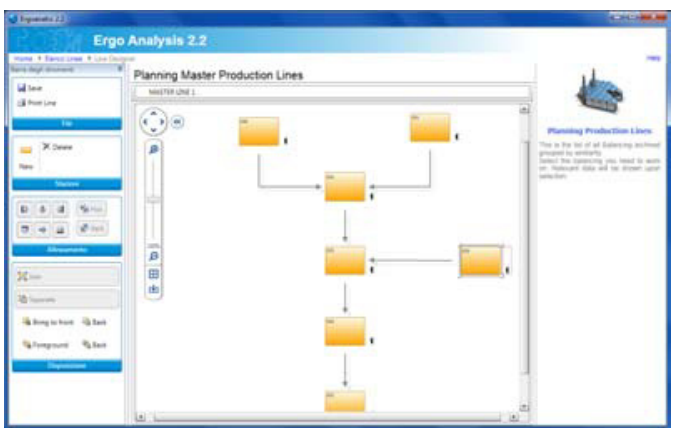

Fig. 1 - ErgoAnalysis: the Production Line Designer

The support to the methodology exposed is a Software Tool named ErgoAnalysis. The software tool has been designed to be a friendly application, fast and essentially intuitive to use, minimizing at most input data sessions. It is the combination of four blocks: the Bill Manager (BM), the Layout Designer (LD), the Risk Assessment Tool (RA) and the Line Balancing Tool (LB). A dedicated database is available in order to provide information and numeric data necessary to complete the set of information for risk assessment and environmental comfort index. Thanks to the Web Architecture, ErgoAnalysis can be used in a geographical distributed environment with one or more supervisor and users. A set of reports provides information both for the workers and the management. Connections to third party software, such as SAP and PDM, are provided via web services.

The user can define, by the BM module, the Bill of Operations, Bill of Materials and Bill of Tools for the particular product or industrial process under examination. Materials and tools can be assigned to each operation by a dedicated interface.

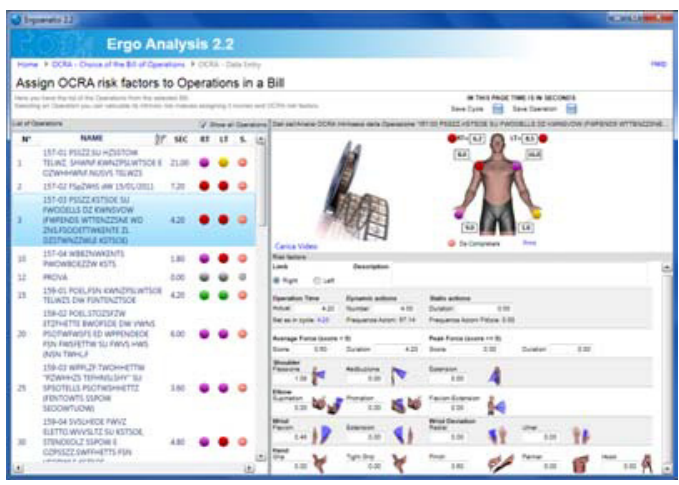

Fig. 2 - ErgoAnalysis: the Risk Assessment Interface
The Production Line Design (Fig. 1) is a graphic designer that let the user define the actual layout of the line under examination. It is possible to design sophisticated layout using a wide range of disposition of workstations.

The RA Tool (Fig. 2) is a complete software interface dedicated to the Risk Assessment of the work activity under examination. A video of the work operation is used to retrieve all risk factors and awkward postures.

The duration of awkward posture is assigned by the user using an integrated chronometer that is synchronized to the video. The duration of the work operation is retrieved directly by the video. For each operation an intrinsic risk is defined.

Line Balancing is made using a dedicated software interface (Fig. 3), by which the Process Engineer can assign operations to the workstations. Operations can be dragged from the list of the defined Bill of Operations and dropped on the assigned workstation. A number of Economic indicators let the user know details about efficiency of the current Line Balancing. It shows how the production line works, how many time lasts each position, which the maximum time for each position. Typical details are: overall line saturation, number of pieces produced by the line, takt-time, bottleneck.

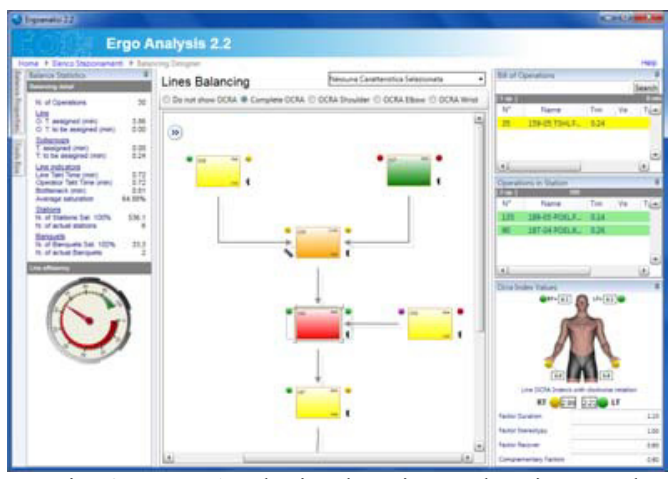

Fig. 3 - ErgoAnalysis: the Line Balancing Tool

As operations are assigned to a workstation a Risk Index is evaluated for it and a colored dot appears at each side of the workstation to indicate the risk level for the combination of operations. Risk Index is made for each methodology used in the Risk Assessment Tool. It is possible to obtain an overall Risk Index in case of Job Rotation among the workstations of the line.

ErgoAnalysis has been adopted by a multinational scooter producer. A database of all operations, materials and tools has been created. Bills of Operations 
have been defined for each product. For each operations the Intrinsic Risk Factor has been evaluated.

In the field of scooter production, due to seasonality, production vary frequently and all Economic and Ergonomic factors vary consequently. In a normal situation at each variation a new Risk assessment should have been done. The use of ErgoAnalysis has permitted a $80 \%$ reduction of costs for new Risk Assessment.

\section{Critical evaluation}

ErgoAnalysis is a software tool that use well known methodology for both risk assessment and line balancing. ErgoAnalysis can assist the Industrial Process Engineer in assigning operations to workstations in the line and in the meantime the WMSDs risk assessment is performed. The use of ErgoAnalysis in many production context where production can vary frequently can lead to a significant cost reduction.

\section{References}

[1] Schaub, K.: Das “Automotive Assembly Worksheet” (AAWS), in Landau, K. (Hg.) Montageprozesse gestalten: Fallbeispiele aus Ergonomie und Organisation, ergonomia Verlag, Stuttgart 2004, p. 91-111

[2] D. Colombini, E. Occhipinti, M. Fanti Il metodo OCRA per l'analisi e la prevenzione del rischio da movimenti ripetuti. Collana Salute e lavoro, Franco Angeli Editore, 2005.

[3] Occupational Safety Tools (OSTools) A complete set for WMSD Risk Assessment. www.liftingindex.com

[4] T.R. Waters, V. Putz-Anderson, A. Garg. An application manual for the revised NIOSH lifting equation. NIOSH Cincinnati, 1994
[5] MTMergonomics ${ }^{\circledR}$ is a joint research project of the Deutsche MTM-Vereinigung and the Institut für Arbeitswissenschaft der TU Darmstadt (Institute of Ergonomics, Darmstadt University of Technology) TiCon ${ }^{\circledR}$

[6] W. Karworski. Handbook on standards and guidelines in ergonomics and human factors.

[7] Jäger, M., Luttmann, A., Göllner, R. and Laurig, W. 2001, The Dortmunder - Biomechanical model for quantification and assessment of the load on the lumbar spine. In: Society of Automotive Engineers (ed.) Digital Human Modeling Conference Proceedings, (SAE, Arlington VA), paper 2001-01-2085, CD-ROM.

[8] Snook SH., Ciriello VM.: The design of manual handling tasks: revised table of maximum acceptable weights and forces. Ergonomics 1991; 34 (9): 1197-1213.

[9] EN 547-3 Safety of Machinery - Human body measurements Part 3: Anthropometric data

[10]EN 614-1 Safety of machinery - Ergonomic design principles - Part 1: Terminology and general principles

[11]EN 614-2 Safety of Machinery - Ergonomic design principles - Part 2: Interaction between the design of machinery and work tasks

[12]EN 1005-2 Safety of machinery - Human physical performance - Part 2: Manual handling of machinery and component parts of machinery

[13]EN 1005-3 Safety of machinery - Human physical performance - Part 3: Recommended force limits for machinery operation

[14]EN 1005-4 Safety of machinery - Human physical performance - Part 4: Evaluation of working postures in relation to machinery

[15]EN 1005-5 Safety of machinery - Human physical performance - Part 5: Risk assessment for repetitive handling at high frequency

[16]EN 1050 Safety of Machinery - Risk assessment

[17] EN ISO 7250 Basic human body measurements for technological design

[18]ISO 11226 Ergonomics - Evaluation of working postures

[19]ISO 11228-1 Ergonomics - Manual handling - Lifting and carrying

[20]ISO 11228-2 Ergonomics - Manual handling - Pushing, pulling and holding

[21]ISO 11228-3 Ergonomics - Manual handling - Handling of low loads at high frequency 